stances, the incorporation of complement components in such interactions has been demonstrated. It is now reported that a correlation can be shown between the amount of such complexes and the diminution in titre of complement activity in joint fluids.

Complement-containing immune complexes have long been known to show phlogistic porperties and their possible role in promoting phagocytosis (with the subsequent release of lysosomal enzymes), in the immune vasculitis which characterizes severe rheumatoid arthritis, and in the possible direct activation of kinins, are topics examined in the concluding sections of the conference.

The papers are accompanied by references to earlier, and to other current, work in this field and also by verbatim accounts of the discussion generated by each paper. This volume therefore serves as an admirable reference source for those actively engaged in this field.

K. W. WALTON

Lubrication and Wear in Joints. Edited by VeRNA Wright. 1970. Pp. 152, 107 figs. Sector Publishing Ltd., London. (53s.)

This book contains the papers given at a Symposium on 'Lubrication and Wear in Joints' held in Leeds in 1969. The papers are grouped broadly into subjects and the discussions which took place at the meeting are accurately recorded after each group of papers. The topic of these papers is the mechanism of lubrication in normal human synovial joints, but there are two chapters dealing with joint simulators built at Leeds and Stanmore for the evaluation of prosthetic joint replacements. A further chapter deals with the requirements of an artificial lubricant for synovial joints; but unfortunately Helal, who has used such lubricants clinically for some years, was not a contributor.

The subject of synovial joint lubrication is a peculiar one. Most of the investigators who have made a material contribution to the subject are either engineers or physicists, since the problem of lubrication is a highly technical one not readily understood by biologists. On the other hand, the interested public consists almost entirely of clinicians who have no understanding of the relevant physical concepts. The discussion therefore tends to consist of a dialogue between experts conducted before a technically uncritical audience. In these circumstances there is a danger that the views of the 'experts' will remain untested since they are not subjected to informed criticism from a substantial body of interested workers. This problem is exacerbated by the fact that relatively few engineers are currently working in the field: of the sixteen chapters in this book, ten were contributed by the groups working at Leeds and Imperial College, London.

The second peculiarity is that there has been a tendency to designate lubrication regimes presumed to be operating in synovial joints by easily memorable terminology. Thus McCutchen introduced the term 'weeping lubrication' and the Leeds workers have now introduced the term 'boosted lubrication'. These terms have the disadvantage that they are susceptible of a wide variety of definitions. Thus at one time. 'weeping lubrication' appeared to imply the expression of fluid from the cartilage matrix into the loaded film (i.e. the cartilage 'wept' into the film), whilst at other times it appeared to be used to describe the opposite possibility in which the film "wept" into the cartilage. Although the symposium which this book reports was conducted at Leeds there is no mention of the Leeds concept of boosted lubrication. This concept rests upon two hypotheses: first that in a loaded film of synovial fluid (between the two surfaces of articular cartilage) the water and small molecular weight solutes in the film pass into the cartilage so as to leave the film itself increasingly concentrated; and secondly that there are pools of synovial fluid trapped between loaded articular cartilage surfaces. The suggestion that synovial fluid becomes ultra-filtered when loaded between surfaces of articular cartilage was first mooted by Ogston, and details of a possible mechanism were advanced by Maroudas in 1967. In the present volume Dr Maroudas advances further data in support of this concept. The idea that pools of synovial fluid are trapped between articular surfaces under load was first put forward in 1968 by Dowson and his co-workers at Leeds. They based this suggestion upon the observation that articular cartilage had a surface substantially rougher than had previously been thought and that, using the scanning electron microscope, it was possible to identify what appeared to be pools of synovial fluid on the cartilage surface. Although it seems very likely that the asperities on the surface cartilage are such as to produce cartilage to cartilage contact only on the apices of asperities, it remains unproven that the fluid in the intervening pools contributes materially to the lubrication regime of synovial joints. To suggest that it does so is to suggest that cartilage surfaces are slippery because they are rough, not in spite of the fact that they are rough. Put in engineering terms, two questions remain unanswered: does the fluid in the allegedly trapped pools contribute to the slipperiness of the synovial surface in any way, and if so does it do so because the fluid itself is pressurized (in which case the lubrication regime is, at least in part, a fluid film one)? Alternatively, does it do so by providing a reservoir of hyaluronic acid which can be transferred by adsorption or otherwise on to the asperities of the opposite surface?

This book provides a series of observations which are to varying degrees relevant to the understanding of the lubrication of synovial joints, but a clear understanding of the likely mechanism does not emerge. Such an understanding is not to be expected at the present time since insufficient data are available and since there is still a measure of disagreement as to certain fundamental observations.

This book represents a valuable introduction to the subject of synovial joint lubrication and contains an excellent list of references. The question however remains unanswered: who should be interested in synovial joint lubrication? Clearly the subject is of physiological interest since it represents an important component in the functioning of the locomotor system. It is far less clear that it represents a subject of clinical interest. It might become so if it could be shown that there was any disease process in man which was due to a breakdown in the normal lubrication regime. If this demonstration were to be made, obviously an understanding of the disease process in question would necessitate a prior understand- 
ing of the normal lubrication regime. The only common disease which might perhaps be attributable to a lubrication breakdown is primary osteoarthrosis. The aetiology of this condition remains obscure, but such observations as have so far been made upon the lubricity of synovial joints early in the osteoarthrosic process suggest that in fact the lubrication regime is undisturbed. Thus it may prove to be the case that no disease process in man is produced by a primary breakdown in the lubrication of synovial joints. This of course is not to say that abrasive wear does not play a part in the destruction of a joint once the cartilage surfaces have been damaged. Indeed inspection of the ebernated, polished bony surfaces of joints in osteoarthrosis strongly suggests that abrasive wear plays a part in the destruction of bone in this disease. It is for this reason that clinical interest is currently being shown in the use of lubricants in the treatment of primary and secondary degenerative joint disease. Here again, however, it is questionable to what extent an understanding of the lubrication regime in normal synovial joints is helpful. By the time a joint is symptomatic the cartilage surfaces have been substantially destroyed and the bearing surfaces are bony. A lubricant which will simulate the lubrication regime in a joint lined by cartilage may therefore be of little or no use in a diseased joint since the latter is lined by bone. From the therapeutic standpoint it would therefore perhaps be more helpful to examine biologically tolerable lubricants for bone to bone surfaces, rather than to try to understand the physiological situation. Such lubricants as have so far been used have been based upon the belief that they in some way simulate synovial fluid: perhaps it is for this reason that they have been relatively ineffective clinically.

M. A. R. FREEMAN

\section{Nederlandse Vereniging van Rheumatologen}

\section{Jan Van Breemen Oration, 1970}

The fifth biennial oration will be delivered on October 31, 1970, at the Amsterdam Rheumatism and Rehabilitation Centre by Dr. B. M. Ansell of Taplow, England.
Further information may be obtained from Dr. K. A. E. Meijers, Boerhaavelaan 182, Leiden, the Netherlands.

\section{Ligue Européenne contre le Rhumatisme}

\section{Bulletin}

In accordance with a request from the Officers of the International League at the Meeting held at Prague in October, 1969, the Bulletin of the European League will in future include scientific papers as well as news and information about the activities of the various national organizations. Correspondence should be addressed to the Secretary-General, who is also the Secretary of the European League, Prof. F. Delbarre, M.D., Hôpital Cochin, Faubourg St. Jacques, Paris XIIIe, France.

\section{European Rheumatology Congress}

\section{Brighton, June 6 to 11, 1971}

The chairman of the organizing committee is Dr. A. G. S. Hill. Full information may be obtained from the Congress Secretariat, c/o M. C. G. Andrews, Arthritis and
Rheumatism Council, Faraday House, 8 Charing Cross Road, London, W.C.2. 